\title{
KONVENCIJA O VARSTVU ALP IN PROTOKOLI - IZHODIŠČA ZA TRAJNOSTNI RAZVOJ V SLOVENSKIH ALPAH IN SOSEDSTVU
}

\author{
Vesna Kolar-Planinšič ${ }^{*}$
}

Izvleček

UDK 711:504.06(234.3)

Prispevek predstavlja mednarodno pogodbo, s katero so se države, ki delijo alpski prostor, zavezale k preudarni in trajni rabi virov in enotni politiki za ohranitev in varstvo Alp. Prikazuje vsebino Alpske konvencije in njene cilje glede prebivalstva in kulture, prostorskega načrtovanja, ohranjanja čistega zraka, varstva tal, vodnega gospodarstva, varstva narave in urejanja krajine, gorskega kmetijstva, gorskega gozda, turizma in prostega časa, prometa, energije in gospodarjenja z odpadki. Podrobneje je predstavljena vsebina protokolov Urejanje prostora in trajnostni razvoj ter Varstvo narave in urejanje krajine, ki se vsebinsko nanašata na trajnostni razvoj in sta krovnega značaja. V svojih ciljih ju zasledujejo tudi vsi drugi protokoli.

Ključne besede: Alpska konvencija, mednarodno sodelovanje, protokoli, trajnostni razvoj, urejanje prostora.

THE ALPINE CONVENTION AND PROTOCOLS - THE STARTING POINTS FOR SUSTAINABLE DEVELOPMENT IN THE SLOVENIAN ALPS AND ITS NEIGHBOURING REGIONS

\section{Abstract}

The article present the international agreement Alpine Convention. The states which have signed the agreement have undertaken to the common politics for the preservation and sustainable use of sources. The areas covered by the convention: population and culture, physical planning, prevention of air polution, soil conservation, water management, nature conservation and landscape planning, mountain farming, mountain forestry, tourism and recreation, transport, energy and waste management are presented as well as their aims. The primary stress is given to the protocols: "Physical Planning and Sustainable Development" and "Nature Conservation and Landscape Planning", with the emphasis to the sustainable development. They represent cover and their aims are implemented in all the others protocols.

Key words: Alpine Convention, international cooperation, protocols, sustainable development, spatial planning.

\footnotetext{
* Mag., svetovalka ministra, Ministrstvo za okolje in prostor, Dunajska 48, 1000 Ljubljana
} 


\section{UVOD}

Že v prejšnjem stoletju so si raziskovalci in prvi gorniki prizadevali, da bi čim bolje spoznali alpski prostor. Potem ko so bile raziskane nekatere posebnosti alpskega prostora, so sledila prizadevanja domačinov, poznavalcev Alp, naravovarstvenikov in gornikov, da bi dele prostora zavarovali in s tem zaščitili pred posegi, ki so že načenjali ta ranljivi ekosistem. $\mathrm{V}$ osemdesetih letih tega stoletja se je uveljavilo spoznanje, da je varstvo Alp možno in učinkovito samo, če se zanj odločijo vse države, ki si delijo alpski prostor (Danz,1989). Na pobudo CIPRE, ${ }^{1}$ ob sodelovanju ARGE-ALP $^{2}$ in z odlokom Evropskega parlamenta o pripravi Konvencije o varstvu Alp (Danz,1989, 413) so se pričele aktivnosti, vključno s Poročili o stanju v alpskem prostoru, ki so jih pripravile posamezne države in pregledom pereče problematike (publikacije CIPRE), ki so pripeljale do sprejetja Konvencije o varstvu Alp. ${ }^{3}$

Alpska konvencija je mednarodna pogodba, ki ima $\mathrm{v}$ primerjavi $\mathrm{z}$ drugimi mednarodnimi pogodbami nekaj posebnosti. $\mathrm{V}$ evropskem, pa tudi $\mathrm{v}$ svetovnem merilu je bilo sklenjenih več mednarodnih pogodb, ki urejajo posamezna vprašanja varstva okolja in narave, Alpska konvencija pa se od njih loči po tem, da s svojimi določbami poskuša zagotoviti trajnostni razvoj na konkretnih gospodarskih področjih (kmetijstvo, gozdarstvo, turizem, energetika, promet) (Ferjančičč, v: Kolar-Planinšič, 1998, 25). Alpska konvencija je izraz konkretnih razmer in potreb v Alpah in se po tem loči od kasneje sprejete Agende 21 (Keating, 1995, 33), ki je bolj okvirna in v poglavju o Trajnostnem razvoju $\mathrm{v}$ gorskih območjih poudarja vlogo in pomen vseh gorskih območij in navaja ukrepe, ki bi jih vlade morale izvajati za zagotovitev trajnostnega razvoja.

Osnovana je tudi na načelu enakopravnosti in zagotavljanju neprekinjenosti samobitnosti prebivalstva in kulture, zato zagotavlja enakopravnost štirih jezikov alpskega loka: slovenskega, francoskega, italijanskega in nemškega.

\section{ORGANIZACIJA IN DELOVANJE}

Najvišji organ je Alpska konferenca, ki zaseda redno na vsaki dve leti pri predsedujoči državi.

\footnotetext{
${ }^{1}$ Commision Internationale pour la Protection des Alpes (Mednarodna komisija za zaščito Alp).

${ }^{2}$ Comunita di Lavoro Delle regioni Alpine (Delovna skupnost osrednjih Alp.

${ }^{3}$ Alpska konvencija ali Konvencija o varstvu Alp, obe imeni sta uradni.
} 
Tako sta bili zadnji dve alpski konferenci v Sloveniji (leta 1996 na Brdu in leta 1998 na Bledu), saj je bila Slovenija štiri leta predsedujoča država. Zasedanj se udeležujejo pogodbenice in podpisnice Alpske konvencije, kot opazovalci pa Združeni narodi in njihove posebne organizacije, Svet Evrope in druge evropske države kot tudi čezmejna združenja teritorialnih skupnosti: Arge $\mathrm{Alp}^{4,} \mathrm{COTRAO}^{5}$ in Alpe-Jadran ${ }^{6}$.

Kot izvšilni organ Alpske konference deluje Stalni odbor Alpske konference, v okviru katerega delegacije podpisnic in pogodbenic konvencije usklajujejo stališča na različnih področjih konvencije ter pripravljajo protokole in delovne programe za izvajanje protokolov.

\section{KONVENCIJA O VARSTVU ALP}

\section{Izhodišča}

Pogodbenice konvencije so Republika Avstrija, Republika Francija, Zvezna republika Nemčija, Republika Slovenija, Kneževina Monaco, Kneževina Liechtenstein, Švicarska konfederacija, podpisnice pa tudi Italijanska republika in Evropska skupnost.

Alpska konvencija temelji na skupnih spoznanjih:

- da so Alpe eden največjih enotnih naravnih prostorov Evrope,

- da jih označujejo raznolika in specifična narava, kultura in zgodovina,

- da pomenijo odličen življenjski, gospodarski, kulturni in sprostitveni prostor $\mathrm{v}$ srcu Evrope, ki si ga delijo mnogi narodi in dežele,

- da so Alpe življenjski in gospodarski prostor domačega prebivalstva,

- da so tudi največjega pomena za zunajalpska območja, med drugim tudi kot nosilec pomembnih prometnih poti,

- da so nepogrešljivo zatočišče in življenjski prostor mnogih ogroženih rastlinskih in živalskih vrst,

- da se zavedajo velikih razlik v posameznih pravnih ureditvah, naravnoprostorskih danostih, poseljenosti, kmetijstvu in gozdarstvu, položaju in razvoju gospodarstva, prometni obremenitvi ter $\mathrm{v}$ vrsti in intenzivnosti turistične rabe,

- da poznajo dejstvo, da stalno naraščajoče zahteve človeka vedno bolj ogrožajo alpski prostor in njegove funkcije in da se škodo da popraviti le izjemoma, $\mathrm{z}$ izrednim trudom, znatnimi stroški in praviloma šele $v$ dolgih časovnih obdobjih in

\footnotetext{
${ }^{4}$ Delovna skupnost osrednjih Alp.

${ }^{5}$ Delovna skupnost zahodnih Alp.

${ }^{6}$ Delovna skupnost vzhodnoalpskega območja Alpe-Jadran.
} 
- da je treba gospodarske interese uskladiti z ekološkimi zahtevami. ${ }^{7}$

Dokument na teh izhodiščih je velikega pomena, saj povezuje z namenom ohranjanja različnosti.

\section{Območje uporabe}

V konvenciji je opredeljeno območje uporabe. V Sloveniji to območje predstavlja $30 \%$ državnega ozemlja in zajema 51 občin.

\section{Cilji konvencije}

Cilj dokumenta je, da pogodbene stranke $\mathrm{s}$ preudarno in trajno rabo virov ter upoštevanjem načela preventive, povzročiteljeve odgovornosti in sodelovanja zagotavljajo enotno politiko za ohranitev in varstvo Alp.

Pogodbenice so se zavezale, da bodo za dosego ciljev posegle po primernih ukrepih na 12 področjih: prebivalstvo in kultura, prostorsko načrtovanje, ohranjanje čistega zraka, varstvo tal, vodno gospodarstvo, varstvo narave in krajinska nega, gorsko kmetijstvo, gorski gozd, turizem in prosti čas, promet, energija, gospodarjenje $\mathrm{z}$ odpadki.

Cilji ukrepov ${ }^{8}$ na področju PREBIVALSTVO IN KULTURA so:

- spoštovanje, ohranjanje, podpiranje kulturne in družbene samobitnosti avtohtonega

- prebivalstva,

- zagotavljanje njegove življenjske osnove, še posebno poselitve in gospodarskega razvoja,

- $\quad$ ki sta znosna okolju,

- pospeševanje medsebojnega razumevanja in partnerskega vedenja med alpskim in zunajalpskim prebivalstvom.

Cilj ukrepov na področju PROSTORSKEGA NAČRTOVANJA je:

- zagotavljanje varčne in preudarne rabe ter zdravega usklajenega razvoja celostnega prostora.

\footnotetext{
${ }^{7}$ Zakon o ratifikaciji Konvencije o varstvu Alp (Alpske konvencije), preambula.

${ }^{8}$ Cilji vseh 12 področij so povzeti po Alpski konvenciji, 2.člen, splošne obveznosti.
} 
Cilja ukrepov na področju OHRANJANJA ČISTEGA ZRAKA sta drastično zmanjšanje emisij škodljivih snovi in obremenitev $\mathrm{z}$ njimi $\mathrm{v}$ alpskem okolju ter njihovo vnašanje od zunaj le do mere, ki ni škodljiva za ljudi, živali in rastline.

Cilj ukrepov na področju VARSTVA TAL je zmanjševanje kvantitativnega in kvalitativnega poškodovanja tal, predvsem z uporabo za tla neškodljivih kmetijskih in gozdarskih proizvodnih postopkov, varčnim ravnanjem $\mathrm{z}$ zemljišči in tlemi, zajezitvijo erozije kot tudi z omejitvijo zaprtja tal.

Cilj ukrepov na področju VODNEGA GOSPODARSTVA je ohranjanje in obnova vodnih sistemov, sonaravna gradnja hidroelektrarn in izkoriščanje vodne sile na način, ki v enaki meri upošteva interese avtohtonega prebivalstva in ohranja okolje.

Cilj ukrepov na področju VARSTVA NARAVE IN UREJANJA KRAJINE je zagotoviti takšno varovanje naravne in kulturne krajine, ki naj trajno zagotavlja sposobnost delovanja ekosistemov, ohranja živalstvo in rastlinstvo vključno z njunim življenjskim okoljem.

Cilj ukrepov na področju GORSKEGA KMETIJSTVA je ohranjanje in pospeševanje gospodarjenja tradicionalnih kulturnih krajin ter kraju primernega in okolju znosnega kmetijstva.

Cilj ukrepov na področju GORSKEGA GOZDA je ohranjanje, krepitev in obnavljanje gozdnih funkcij, še posebno varovalnih funkcij, zlasti s sonaravnim gozdnim gospodarjenjem in preprečevanjem gozdu škodljive rabe.

Cilj ukrepov na področju TURIZMA in PROSTEGA ČASA je usklajevanje turističnih in sprostitvenih dejavnosti $\mathrm{z}$ ekološkimi in družbenimi zahtevami, $\mathrm{z}$ omejevanjem dejavnosti, ki škodijo okolju, ter še posebno $z$ določanjem območij miru.

Cilj ukrepov na področju PROMETA je zmanjševanje obremenitev in nevarnosti $\mathrm{v}$ prometu v Alpah do stopnje, ki je še znosna človeku, živalim, rastlinam ter njihovim življenjskim prostorom. To je med drugimi mogoče doseči s preusmeritvijo prometa, predvsem tovornega, na železnico ter z ustvarjanjem primernih infrastruktur.

Cilj ukrepov na področju ENERGIJE je pridobivanje, razdeljevanje in izkoriščanje energije na način, ki prizanaša naravi in pokrajini in je neškodljiv okolju ter pospeševanje ukrepov za varčevanje $\mathrm{z}$ energijo.

Cilj ukrepov na področju GOSPODARJENJA Z ODPADKI je zagotavljanje zajemanja, predelave in odstranjevanja odpadkov, ki je prilagojeno posebnim 
topografskim, geološkim in klimatskim potrebam alpskega okolje, ob doslednem upoštevanju omejevanja odpadkov. ${ }^{9}$

\section{PROTOKOLI ZA TRAJNOSTNI RAZVOJ V ALPAH}

K Alpski konvenciji so bili oblikovani protokoli. Izdelani so bili $\mathrm{v}$ mednarodnih delovnih skupinah, preverjeni na Stalnem odboru in sprejeti na ministrskih konferencah. Na III. ministrski konferenci v Chamberyju v Franciji sta bila leta 1994 sprejeta protokola Urejanje prostora in trajnostni razvoj in Varstvo narave in urejanje krajine, na IV. alpski konferenci na Brdu leta 1996 protokola Gorski gozd in Turizem in na V. alpski konferenci na Bledu leta 1998 protokola Energija in Varstvo tal.

Protokoli so bili oblikovani s soglasjem vseh sodelujočih. Protokoli se po vsebini prepletajo, krovna po vsebini pa sta Urejanje prostora in trajnostni razvoj ter Varstvo narave in urejanje krajine.

\section{Protokol Urejanje prostora in trajnostni razvoj ${ }^{10}$}

Protokol temelji na spoznanju, da je alpski prostor območje, ki je pomembno za vso Evropo in je po reliefu, podnebju, vodovju, rastlinstvu, živalstvu in pokrajini tako edinstvena kot tudi raznovrstna dediščina, in da njeno gorovje, doline in predalpsko hribovje sestavljajo ekološke enote, katerih ohranitev ni koristna le za alpske države. ${ }^{11}$

Protokol uveljavlja tudi pojem trajnostnega razvoja (sustainable development ${ }^{12)}$, ki ga v slovenskem jeziku prevajamo tudi kot uravnoteženi, trajno uravnoteženi, sonaravni, vzdržni, usklajeni, zdravi in obstojni, okolje ohranjajoči, trajnostni razvoj (Barbič in sod., 1997, 41). Pojem je uvedla Svetovna komisija za okolje in razvoj (Brutlandova komisija) (World Commission on Environment and Development, 1987) in se pojavlja v številnih mednarodnih dokumentih in publikacijah, ki iz njih izhajajo, med drugim tudi v Alpski konvenciji.

\footnotetext{
${ }^{9}$ Alpska konvencija, 2.člen.

${ }^{10}$ Ta protokol in vse ostale v besedilu omenjene protokole je Slovenija podpisala, niso pa še ratificirani.

${ }^{11}$ Protokol Urejanje prostora in trajnostni razvoj, preambula.

${ }^{12}$ Opredeljen je kot «razvoj, ki omogoča zadovoljevanje potreb sedanjih generacij, ne da bi bile s tem ogrožene možnosti prihodnjih generacij pri zadovoljevanju njihovih potreb» (Our Common Future, 1987). Po opredelitvi iz publikacije Caring for Earth (IUCN/UNEP, 1991) trajnostni razvoj omogoča izboljšanje človekovega življenja ob ohranjanju nosilnih sposobnosti zemlje, podlaga za njegovo udejanjanje pa je trajnostna družba. Obstajajo tudi številne znanstvene razprave, ki opredeljujejo pojem.
} 
Protokol opredeljuje cilje urejanja prostora, ki so:

- priznavanje posebnih zahtev alpskega prostora $\mathrm{v}$ okviru nacionalnih in evropskih politik,

- prilagajanje rabe prostora ekološkim ciljem in zahtevam,

- varčna in okolju sprejemljiva raba virov in prostora,

- priznavanje posebnih koristi alpskega prebivalstva in prizadevanje za trajno zagotavljanje podlage za njihov razvoj,

- pospeševanje gospodarskega razvoja ob hkratnem uravnoteženem demografskem razvoju v alpskem prostoru,

- ohranjanju pokrajinskih značilnosti in kulturnih posebnosti, pospeševanju enakih razvojnih možnosti za tamkajšnje prebivalstvo na družbenem, kulturnem in gospodarskem področju ob upoštevanju pristojnosti teritorialnih skupnosti,

- 1. upoštevanje naravnih omejitev, storitev splošnega pomena, omejitev rabe naravnih virov in upoštevanje ekonomske cene za rabo teh virov.

V protokolu so natančneje navedene temeljne obveznosti za dosego ciljev in posebni ukrepi za načrte in programe za urejanje prostora in trajnostni razvoj.

Tabela 1: Protokoli Alpske konvencije

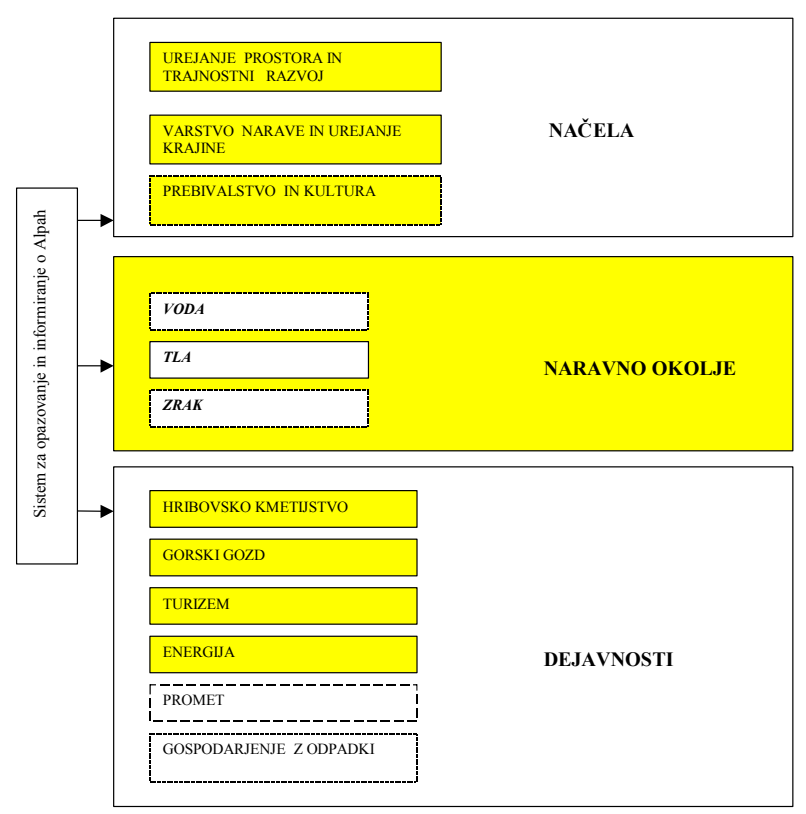




\section{Protokol Varstvo narave in urejanje krajine}

Protokol kot obveznost navaja posnetek stanja in zasnove, programe oz. načrte, s katerimi opredelijo zahteve in ukrepe za uresničitev varstva narave in urejanja krajine.

Pogodbenice so se zavezale, da bodo na podlagi krajinskega načrtovanja in v skladu s prostorskim načrtovanjem sprejele vse potrebne ukrepe za ohranitev in izboljšanje naravnega in sonaravnega življenjskega okolja prosto živečih živalskih in rastlinskih vrst, kakor tudi za druge značilne sestavine naravne in kulturne krajine.

Protokol navaja ukrepe za temeljno varstvo, za zavarovana območja, za povezanost določenih zavarovanih območij, za varstvo tipov biotopov in rastlinskih in živalskih vrst, ukrepe glede lova , prilaščanja, poškodovanja in ubijanja nekaterih živalskih vrst, ukrepe glede trgovanja, ponovnega naseljevanja samoniklih vrst, prepovedi naseljevanja in širitve genetsko spremenjenih organizmov.

\section{Hribovsko kmetijstvo}

Protokol temelji na izhodišču, da morajo biti interesi gospodarstva usklajeni $\mathrm{z}$ ekološkimi zahtevami, pri čemer je treba upoštevati posebnosti posameznih regij in osrednjo vlogo kmetijstva. Predvideva ukrepe na mednarodni ravni, s katerimi bi ohranjali pomen kmetijstva kot temelja za ohranjanje primerne gostote poseljenosti, preskrbo prebivalstva s hrano, proizvodnjo kakovostnih tipičnih proizvodov, ohranjanje in vzdrževanje kulturne pokrajine, med drugim tudi zaradi turistične rabe in varstva tal pred erozijo, plazovi in poplavami.

Pogodbenice so se dogovorile, da bodo med drugim:

- skupaj presojale razvoj kmetijske politike in se medsebojno posvetovale pred vsako pomembno odločitvijo ,

- s čezmejnim sodelovanjem zagotavljale uresničevanje ciljev in ukrepov, določenih v tem protokolu,

- pospeševale izmenjavo znanja, izkušenj in skupnih pobud z mednarodnim sodelovanjem med raziskovalnimi in izobraževalnimi zavodi, kmetijskimi in okoljskimi organizacijami kot tudi občili.

Protokol našteva ukrepe za pospeševanje hribovskega kmetijstva, za smotrno urejanje prostora in krajine, za sonaravno gospodarjenje, za pospeševanje kraju primerne živinoreje, za zagotavljanje genetske raznolikosti živine in kulturnih rastlin, za trženje, omejitev proizvodnje, dopolnjevanje kmetijstva in gozdarstva, za 
zagotavljanje dodatnih virov zaslužka in za izboljšanje življenjskih in delovnih razmer.

K protokolu so priložene prednostne raziskovalne in izobraževalne teme.

\section{Gorski gozd}

Protokol temelji na izhodišču, da je gorski gozd oblika vegetacije, ki zagotavlja najučinkovitejše, najcenejše in krajinsko najprimernejše varstvo pred naravnimi nevarnostmi, poleg tega pa zagotavlja vrsto drugih funkcij (Golob, v Kolar-Planinšič, 1997, 64).

Cilj protokola je zagotoviti ohranitev in stabilnost gorskega gozda s sonaravnim gospodarjenjem in ustrezno politiko na drugih področjih. Zato predvideva vrsto posebnih ukrepov.

\section{Turizem}

Cilj protokola je $\mathrm{v}$ obstoječem pravnem okviru prispevati $\mathrm{k}$ trajnostnemu razvoju alpskega prostora $\mathrm{z}$ okolju primernim turizmom, z obvezujočimi ukrepi in priporočili, ki upoštevajo interese domačinov in turistov.

Posebni ukrepi navajajo obveznosti glede obvladovanja ponudbe, usmeritve razvoja turizma, prizadevanja za kakovost, usmerjanje turističnih tokov, omejitve razvoja zaradi naravnega okolja, za določitev območij miru, politiko razvoja prenočitvenih zmogljivosti. Pri postavitvi žičniških naprav bodo podpisnice $\mathrm{v}$ okviru domačih postopkov za izdajanje dovoljenj uveljavljale politiko, ki ustreza okoljevarstvenim zahtevam, zahtevam pokrajine ter varnosti in gospodarnosti. Pogodbenice bodo spodbujale omejevanje prometa $\mathrm{z}$ motornimi vozili $\mathrm{v}$ turističnih središčih, smotrno urejanje smučišč in razporejanje počitnic, investicije ter sodelovanje med turizmom, kmetijstvom, gozdarstvom in obrtjo.

\section{Varstvo tal}

Protokol je namenjen uresničevanju obveznosti do varstva tal, ki izvirajo iz Alpske konvencije. Cilj je varovanje tal v njihovi naravni funkciji, v funkciji arhiva naravne in kulturne zgodovine in $\mathrm{z}$ vidika zagotavljanja različne rabe. 
Navaja ukrepe, ki so usmerjeni v kraju primerno rabo, varčno ravnanje s površinami, preprečevanje erozije in negativnih sprememb strukture tal, $\mathrm{k}$ zmanjševanju vnašanja obremenilnih snovi v tla ter k ohranjevanju raznolikosti tal in značilnih območij.

Pogodbenice se v protokolu zavezujejo, da bodo pri določitvi zavarovanih območij upoštevale tudi tla in njene značilne posebnosti, varčno in neškodljivo ravnale s tlemi, skrbele za varčno uporabo in tlem neškodljiv izkop rudnih bogastev, ohranile tla na mokriščih in barjih ter kartirale alpska območja, ki jih ogrožajo geološke, hidrogeološke in hidrološke nevarnosti.

Pogodbenice bodo na podlagi primerljivih metod za določanje obsega erozije tal kartirale

alpske območja in omejile erozijo na najmanjšo možno mero, uporabljale pa bodo tudi dobro, krajevnim razmeram prilagojeno poljedeljsko, pašniško in gozdarsko prakso. Omejile bodo vpliv turistične infrastrukture na alpska tla, zmanjšale uporabo soli za posipanje in jo zamenjale s primernejšimi sredstvi.

Pogodbenice bodo spodbujale sodelovanje pri raziskavah in opazovanju, izdelavo usklajenih podatkovnih baz in ureditev površin za stalno opazovanje ter obveščale javnost o ciljih, ukrepih in izvajanju tega protokola.

\section{Energija}

Obveznost, ki izhaja iz tega protokola, je ustvarjanje takih okvirnih razmer in sprejetje takih konkretnih ukrepov za varčevanje $\mathrm{z}$ energijo, za njeno proizvodnjo, prenos, distribucijo in rabo, da bi ustvarile energetske razmere za trajnostni razvoj $v$ skladu z obremenitvami, ki so sprejemljive za alpski prostor.

Temeljne obveznosti so: usklajevanje načrtovanja $\mathrm{v}$ energetiki s splošnim prostorskim planiranjem $\mathrm{v}$ alpskem prostoru, usmerjanje sistemov za proizvodnjo, prenos in distribucijo energije $\mathrm{v}$ splošno preoblikovanje celotnega infrastrukturnega sistema $\mathrm{v}$ alpskem prostoru ob upoštevanju varstva okolja, zmanjševanje obremenitev okolja, presoja vplivov na okolje pri gradnji velikih energetskih infrastruktur, spodbujanje rabe obnovljivih virov energije in razvoj ustrezne raziskovalne in razvojne politike s preventivnimi in sanacijskimi ukrepi ter sodelovanje pri razvijanju metod, ki bolj upoštevajo dejanske stroške.

Protokol navaja potrebo po skladnosti z mednarodnim pravom in s politiko na drugih področjih ter sodelovanje teritorialnih skupnosti.

Navaja vrsto posebnih ukrepov za prihranek energije in racionalnejšo rabo ter poudarja prednostno rabo energije iz obnovljivih virov. Posebna določila protokola so 
namenjena vodni energiji, energiji iz fosilnih goriv, jedrski energiji, prenosu in distribuciji energije, renaturaciji in sonaravni tehnologiji ter presoji vplivov na okolje.

Sodelovanje pri raziskavah, opazovanju, izobraževanju in obveščanju je obveznost, ki izvira iz vseh protokolov in je delno povezana tudi s sodelovanjem pri Sistemu opazovanja in obveščanja o Alpah.

\section{Raziskave in sistematična opazovanja}

Pogodbenice na navedenih področjih izvajajo raziskovalna dela in znanstvena ocenjevanja, razvijajo skupne projekte in dopolnitvene programe za sistematično opazovanje.

$\mathrm{Na}$ IV. alpski konferenci na Brdu je bil vzpostavljen Sistem za informiranje in opazovanje v Alpah (SOIA)13.

Po prvih petih opravljenih pilotnih projektih (Seznam organizacij za raziskave o Alpah, Sociodemografski kazalci, Kartografija socio-demografskih kazalcev, Katalog virov podatkov o Alpah in Telematske komunikacije) (Jančič, v Kolar-Planinšič, 1997, 91) SOIA nadaljuje $\mathrm{z}$ delom na naslednjih šestih področjih dejavnosti: opredelitev in izdelava okoljskih kazalcev, opredelitev in izdelava socio-ekonomskih kazalcev, posodobitev in izpopolnitev dopolnilnega modula za Sistem za informiranje o raziskavah Alp (SIRA), izdelava kataloga podatkovnih virov o Alpah (CSDA) in alpskega slovarja (thesaurus alpini), izdelava osnovne kartografije in kartografskega prikaza kazalcev ter ureditev računalniško podprtega komunikacijskega sistema.14

\section{Sodelovanje na pravnem, znanstvenem, gospodarskem in tehničnem področju}

Po konvenciji pogodbenice olajšujejo in pospešujejo izmenjavo pravnih, znanstvenih, gospodarskih in tehničnih informacij, ki so pomembne za konvencijo, se med seboj obveščajo o načrtovanih, pravnih in gospodarskih ukrepih, ki lahko vplivajo na alpski prostor ali njegove dele, pri tem pa $\mathrm{v}$ največji možni meri upoštevajo čezmejne in regionalne zahteve. Po potrebi pogodbenice sodelujejo z mednarodnimi vladnimi in nevladnimi organizacijami ter poskrbijo za tekoče obveščanje javnosti in prebivalstva o rezultatih raziskav in opazovanj ter o sprejetih ukrepih. Tako poteka preko dela

\footnotetext{
${ }^{13}$ Predstevitev sistema je na spletni strani na naslovu: http://rea.ei.jrc.it/ap/SOIA/en/pp1.html ${ }^{14}$ Poročilo o Sistemu za opazovanje in informiranje o Alpah (SOIA) za V. Alpsko konferenco (16.oktober 1998).
} 
Stalnega odbora intenzivno sodelovanje $z$ ustanovami CIPRA, IUCN, ARGE-ALP, FIANET-om in EUROMONTANA.

\section{SKLEP}

Alpska konvencija je okvirni dokument, ki s protokoli sicer pomeni obveznost za države, vendar hkrati navaja, da so lahko varovalni instrumenti v posameznih državah še strožji. Tako pri pogajanjih posamezna država ali nevladna organizacija marsikdaj ni bila zadovoljna s sprejetim besedilom, češ da je preveč načelno. Ista določila pa lahko v drugi državi povzročijo vrsto posledic. Vendar je ta dokument prerez sedanjega stanja alpskih državah in dosežena določila največji možni kompromis.

Konvencija se na nekaterih področjih že udejanja, sprejeti so tudi že programi za izvajanje, npr. Program za udejanjanje protokola varstvo narave in urejanje krajine, ki sta ga pripravili Francija in Nemčija. Dejavnosti potekajo tudi v mnogih nevladnih organizacijah . Pred javno upravo ter znanstveno-raziskovalno in izobraževalno sfero je dolga pot za dosego trajnostnega razvoja v Alpah; skupni cilj bomo poskušali doseči po različnih poteh in z željo po sinergetskem učinku.

\section{VIRI IN LITERATURA}

1. Agenda 21 za Slovenijo, 1995: Prispevek nevladnih organizacij. Umanotera, Ljubljana.

2. CIPRA, 1991: Življenje za naše alpske reke. Ministrstvo za okolje in prostor, Ljubljana.

3. Danz W., 1989: Umweltpolitik im Alpenraum. CIPRA, München.

4. Danz W., Ortner S., 1993: Die Alpenkonvention-eine Zwischenbilanz. Mednarodna komisija za varstvo Alp. Munchen.

5. Keating M., 1995: Agenda za spremembo s Srečanja na vrhu. Umanotera. Ljubljana.

6. Kolar-Planinšič V., 1997: Alpska konvencija v Sloveniji. Ministrstvo za okolje in prostor, Ljubljana .

7. Nouvelles modalites d'utilisation de l'espace alpin, 1996. ForumAlpin, Revue de Geographie Alpine supplement au N.4, Chamonix.

8. Premzl V., Rezman V., 1998: CIPRA, Prvo poročilo o Alpah, podatki, dejstva, problemi, rešitve. Maribor. 
9. The World Commission on Environment and Development, 1987: Our Common Future. Oxford University Press, Oxford.

10. Zakon o ratifikaciji Konvencije o varstvu Alp (Alpske konvencije). Uradni list RS št. 19, Mednarodne pogodbe, Vol.V, št. 5, 31. Marec 1995.

\title{
THE ALPINE CONVENTION AND PROTOCOLS - THE STARTING POINTS FOR SUSTAINABLE DEVELOPMENT IN THE SLOVENIAN ALPS AND ITS NEIGHBOURING REGIONS
}

\begin{abstract}
Summary
In contrast to other international endeavours to ensure sustainable development of the mountain areas, the Alpine Convention has certain particular features. Several international agreements have been concluded in worldwide, but the Alpine Convention displays an essentially different approach to ensuring sustainable development oriented towards protection and development in the heart of Europe.

The Alpine Convention entered into force in March 1995, following its ratification by the parliaments of Austria, France, Germany, Liechtenstein and Slovenia The highest body is the Conference of Contracting Parties (the Alpine Conference), while the executive body is The Standing Committee which cooperate with the international government and non-government organisation and the transborder associations of territorial communities.
\end{abstract}

The main aim of the article is presentation of the areas covered by the Alpine Convention and its aims as well as presentation of detailed Protocols and implementation programmes.

The Physical Planning and Sustainable Development protocol and Nature conservation and Landscape planning protocol are the most important adopted protocols while they are covers and their aims are adopted in all the further protocols.

.During the Slovene presidency of the Alpine Conference, interest in the sustainable development in alpine area has been growing on many levels including international and slovene professional public. This is also the special reason for the presentation of the Alpine Convention and its protocols is the article.

While the adopted protocols represent the statements of experts and states about sustainable use, the long-term conflict solving on the case of protocol Transport 
represents also the wide range of problems, dilemas and conflicts on the way toward sustainable development . 